\section{Bio-C Repair - A New Bioceramic Material for Root Perforation Management: Two Case Reports}

Kênia Soares de Toubes ${ }^{1}$ (DD, Stephanie Quadros Tonelli ${ }^{\mathbb{D}}$, Caroline Felipe Magalhães Girelli ${ }^{1}$ D , Camila Grasielle de Sá Azevedo ${ }^{1}$ (D), Ana Carolina Tocafundo Thompson ${ }^{1}$ (D), Eduardo Nunes ${ }^{1}$ DD, Frank Ferreira Silveira ${ }^{1}$ (D)
'Department of Dentistry, PUC Minas - Pontifícia Universidade Católica de Minas Gerais, Belo Horizonte, MG, Brazil

Correspondence: Dr. Frank Ferreira Silveira. Avenida Dom José Gaspar 500 / Prédio 46, 30535-610 Belo Horizonte, MG, Brasil. Tel: +55-31- 3319-4414. e-mail: frankfoui@uol.com.br

\begin{abstract}
These case reports aimed to describe the management of lateral perforation in the middle cervical third of the root in two maxillary incisors with pulp canal calcification using Bio-C Repair, with safe and viable clinical treatment strategies. Digital radiographic exams were obtained with different angles and analyzed using different filters. Cone-beam computed tomography (CBCT) images were requested to show the actual position of the canal, location of the perforation, and guide the strategic planning of the case. Subsequently, cavity access was prepared with the aid of dental operating microscopy. After perforation was identified, granulation tissue was removed and the original canal was identified and then dressed with calcium hydroxide. In the second visit, the perforation was filled with Bio-C Repair and the canal system filled with gutta-percha points and a root canal sealer (Bio-C Sealer). The teeth were restored with glass fiber post, $4 \mathrm{~mm}$ beyond the perforation level, and provisory crowns. Both teeth treated as described above were functional and asymptomatic with a 1-year clinical and radiographic assessment. The Bio-C Repair is suggested as a new cement option for the management of lateral canal perforations, with effective results as observed after a one-year follow-up.
\end{abstract}

Key Words: bioceramic, dental pulp cavity, endodontics, perforation, tricalcium phosphate.

\section{Introduction}

In endodontic practice, accidents and complications, such as root perforation, require the use of biocompatible materials that induce tissue repair. In this context, mineral trioxide aggregate (MTA) has traditionally been considered the first choice for endodontic repair $(1,2)$. However, even though this material has undergone several improvements in composition, MTA has certain limitations, such as tooth discoloration, handling difficulties, prolonged setting time, and the release of heavy metals (3).

Due to the need to improve these properties, bioceramics have undergone several changes in composition, particle size, and presentation $(4,5)$. Bioceramics consist of calcium silicates, calcium phosphate, calcium hydroxide, zirconium oxide, tantalum oxide, putties, and thickeners $(5,6)$. The distribution and particle size of tricalcium silicate powders affect handling and setting properties, since smaller particles can penetrate dentin tubules, leading to quicker hydration $(7,8)$. Also, zirconia oxide, used as a radioopacifier, was detected at high levels in Bio-C Repair and Biodentine cement when compared with ProRoot MTA (9). This component is associated with the prevention of tooth discoloration (10). Bioceramic cements present potential bioactivity, that is, the capacity to produce hydroxyapatite, influencing the connection between dentin and filling material $(11,12)$. These materials are chemically stable, may aid in increasing root fracture resistance, exhibit good radiopacity, have a high $\mathrm{pH}$, are easy to handle, and do not undergo resorption. Moreover, these materials interact with stem cells from periapical tissues, producing a biological seal, and inducing the repair process (13). MTA High-plasticity (MTA-HP) and EndoSequence Root Repair Material Putty are repair cement well recognized in the literature as efficient bioceramic materials for complex cases, as they have been shown to aid in the reparative response $(13,14)$.

Recently, Bio-C Repair (Angelus, Londrina, Brazil), a new ready-to-use bioceramic material, was introduced to endodontics in a threaded syringe, which offers handling and insertion improvements, collaborating with the practice and saving time. This material has similar cytotoxicity, biocompatibility, and biomineralization properties to MTAHP and white MTA (15). In stem cells from the periodontal ligament, Bio-C Repair and Bio-C Sealer had similar pHs, but Bio-C Repair exhibited greater cell viability and cell adhesion, indicating its bioactivity. This cement showed excellent cytocompatibility, similar to Biodentine and ProRoot MTA when used with a chemical technique and ultrastructural morphology on human dental pulp cells (9).

Despite most studies attesting to the suitable behavior of bioceramics for repair in endodontics, there is a lack of reports on the use of Bio-C Repair for perforations, 
especially concerning anterior teeth. In this context, this study aimed to describe the management of two clinical root perforation cases of anterior teeth sealed with Bio-C Repair.

\section{Case Report}

\section{Case 1}

A healthy 62-year-old male patient was referred to the endodontic clinic at the Pontifical Catholic University of Minas Gerais (PUC Minas, Belo Horizonte, MG, Brazil) for the diagnosis and treatment of persistent swelling on the buccal side of tooth \#12 (according to the FDI notation). His medical history was noncontributory. Clinical examination revealed a sinus tract in the region of the referred tooth (\#12) (Fig. 1a), although there was

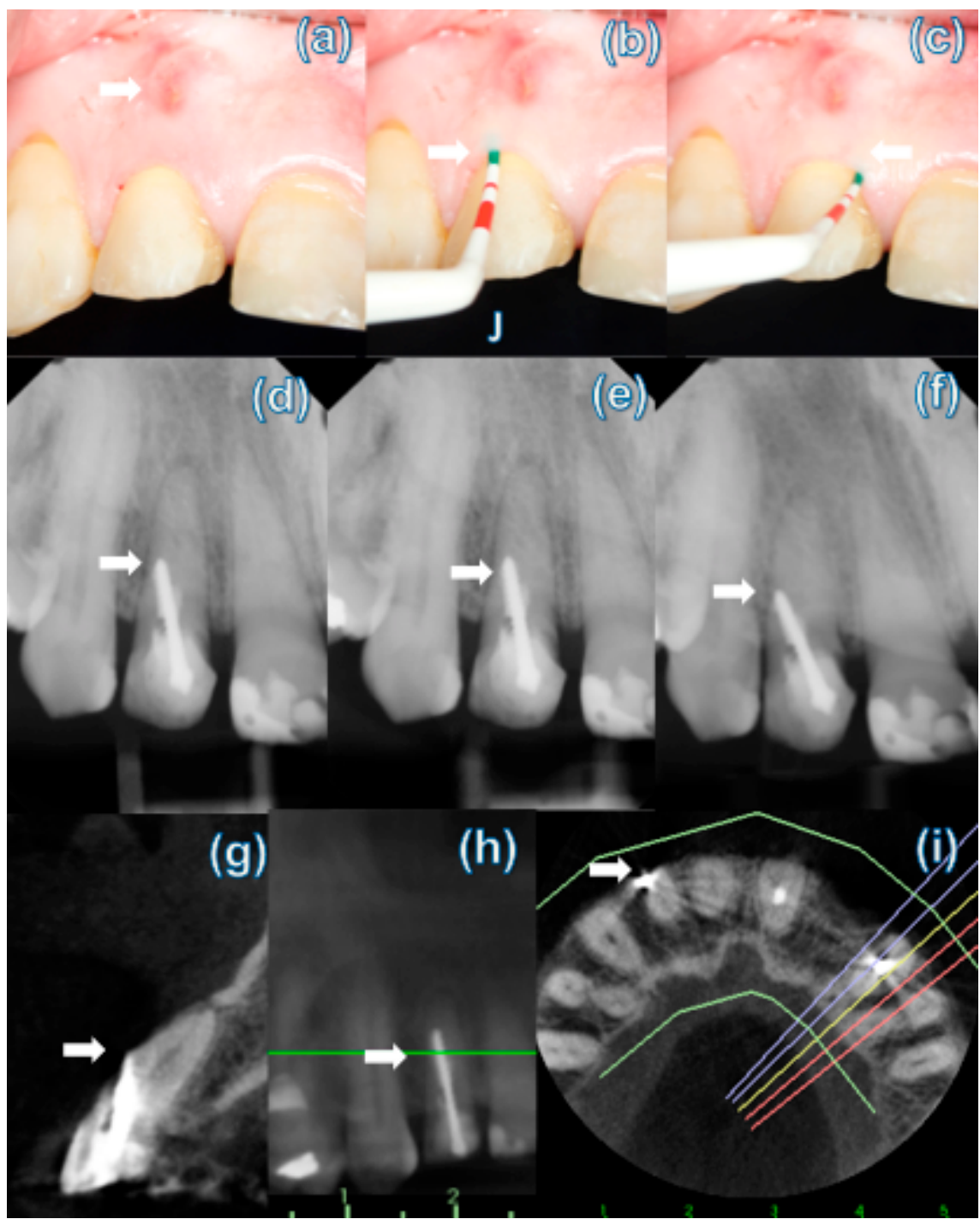

Figure 1: maxillary right lateral incisor preoperative image indicating the presence of sinus tract in the buccal mucosa of the root middle cervical third (arrow) (a). No periodontal pocket was identified (arrows) (b,c). Preoperative periapical radiographs at different angulations showing intra-canal post displacement outside the long root axis (arrows) (d,e,f). CBCT sagittal and axial slices: buccal perforation in the cervical third of the root was confirmed (arrows) (g,h,i). no significant periodontal probing depth (Fig. 1b, 1c) and no pain symptoms were reported.

Digital radiographs (DR) (Digital System XDR ${ }^{\oplus}$, São Paulo, Brazil) were taken of the ortho, distal, and mesial angulations, which suggested pulp canal calcification (PCC) and the presence of an intracanal post diverted to buccal tooth \#12 (Fig. 1d-1f). To better understand this case, cone beam computed tomography (CBCT) was requested. The images were analyzed and the sagittal, coronal, and axial images confirmed the presence of both perforation and PCC (Fig. 1g-1i). The clinical findings and prognosis were explained to the patient, and his consent for the procedures was obtained.

Endodontic retreatment procedures were performed by dental operating microscopy (DF Vasconcelos, São Paulo, Brazil) in two sessions. The patient was anesthetized using a $2 \%$ lidocaine infiltration with epinephrine, 1:200,000 (Alphacaine; DFL, Rio de Janeiro, RJ, Brazil), and a rubber dam (Hygenic ${ }^{\circledR}$, Coltene ${ }^{\circledR}$ Switzerland) was placed on tooth \#12 and fixed with Top $\operatorname{Dam}^{\circledR}$ gingival barrier (FGM, Joinville, $\mathrm{SC}$, Brazil) on the adjacent teeth (Fig. 2a). Access to the pulp chamber cavity was performed by palatine, and the intracanal post (Fig. 2b) was carefully removed using an ultrasonic tip (ST09) coupled to an ENAC ultrasound device (Osada, California, USA) (Fig. 2c). The pulp chamber was then irrigated with 5.25\% sodium hypochlorite (Lenza Pharma, MG, Brazil), and the remaining debris was removed using ultrasonic inserts. The region was dried, and the buccal perforation was identified (Fig. 2d). A previously suggested protocol was adopted for PCC identification (16). After identification of the correct canal position (Fig. 2e), a \#10 C PILOT file (VDW ${ }^{\circledR}$, Munich, Germany) was introduced using clockwise movements, and the canal work length was confirmed using the Root ZX2 electronic apex locator (J Morita, Osaka, Japan) and radiographic images (Fig. 2f, 2g). Root canal preparation was performed using the rotatory NITI ProTaper NEXT ${ }^{\circledR}$ 


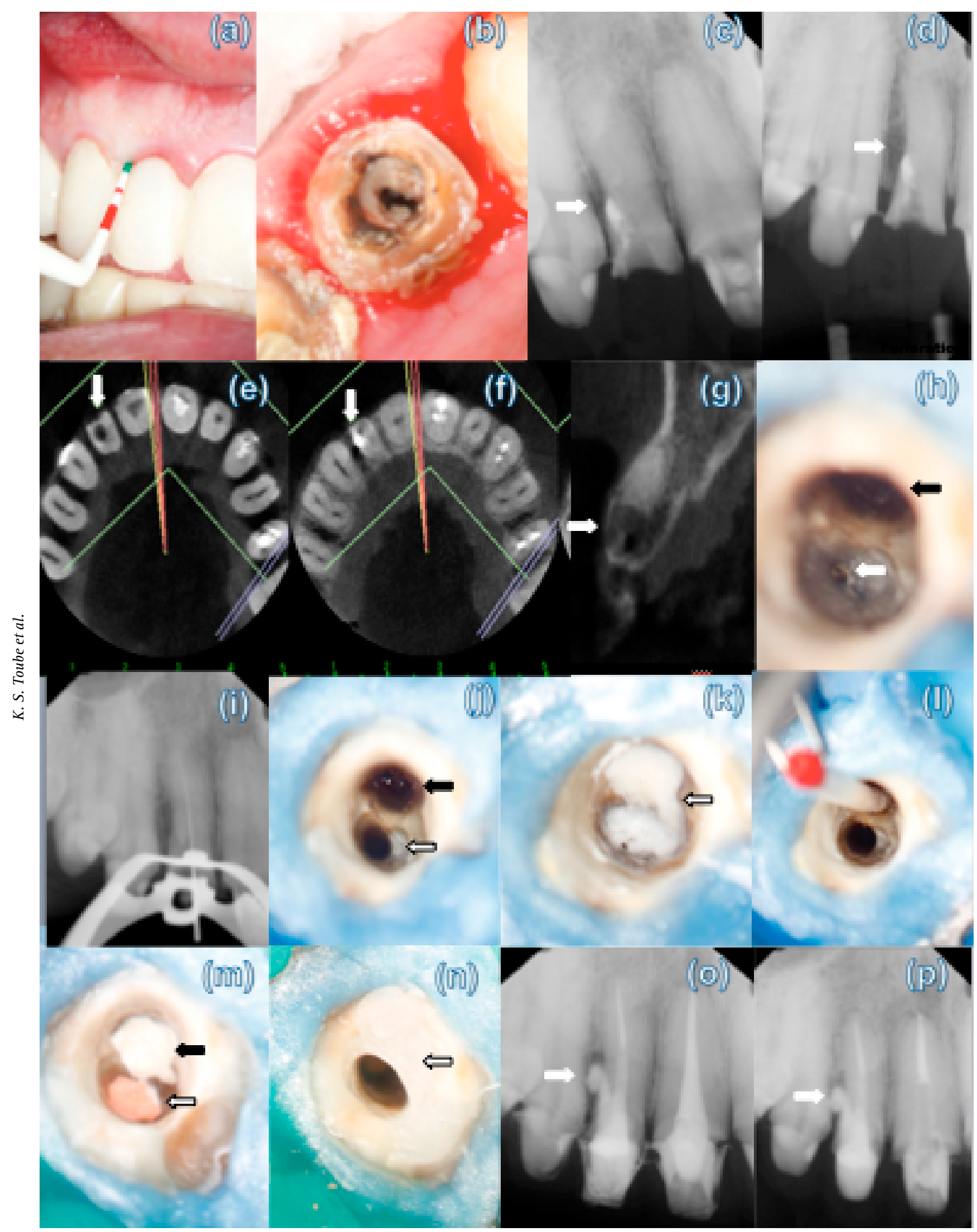

Figure 2: Rubber Dam placed on the adjacent teeth (a). The intra-canal post was visualized and carefully removed under DOM, using an ultrasonic tip (b,c). Clinical aspect of the perforation (black arrow) (d). The root canal entrance (arrow) (e). Radiography determination of working length $(\mathrm{f}, \mathrm{g})$. The canal was cleaned and shaped using the ProTaper NEXT ${ }^{\circledR}$ files (h). Radiography and clinical evaluation of the master cone (j,k). Root canal obturation (White arrow) (l). Perforation filled with Bio-C repair (black arrow) (m). Postoperative radiography was taken after the placement of Bio-C Repair (n,o). Digital radiographic follow-up after one- year of treatment (p). 
$\mathrm{X} 1, \mathrm{X} 2$, and X3 (Dentsply Maillefer, Ballaigues, Switzerland) copiously irrigated with $5.25 \%$ sodium hypochlorite (Fig. $2 \mathrm{~h}, 2 \mathrm{i})$. Subsequently, the canal was rinsed with $17 \%$ ethylenediaminetetraacetic acid (EDTA) (Lenza Pharma) for $1 \mathrm{~min}$. Final irrigation was performed with sodium hypochlorite and activated with ultrasound tips (Helse, São Paulo, Brazil). Subsequently, the canal and the perforation were dried with absorbent paper tips and dressed using a dressing of calcium hydroxide (Lenza Pharma) mixed with distilled water. A small sterile cotton ball was placed in the pulp chamber, which was then sealed with the double provisional restorative materials Coltosol (Coltene, Whaledent, USA) and Flow Surefil resin (Dentsply Caulk, Derbyshire, England).

After 14 days, under a dental operating microscope (DOM), the calcium hydroxide dressing was removed and the site was irrigated again with sodium hypochlorite and EDTA (Lenza Pharma). Upon the removal of the interim material, and the perforation was free of bleeding. While performing the obturation, a small cotton ball was used to seal the perforation. A DR was performed to confirm the cone master (Fig. 2j, 2k). The canal was obturated with gutta-percha and a bioceramic sealer (Bio-C Sealer; Angelus, Londrina, Brazil) (Fig. 2l). Subsequently, the cotton ball was removed, and the perforation was sealed with Bio-C Repair (Angelus), with an MTA micro-carrier (Angelus) and condensed with hand pluggers. A cotton ball was moistened with distilled water and kept on the material and the placement of the material was confirmed radiographically (Fig. $2 m-20$ ). At the next appointment, the provisional material was removed, and the setting of the bioceramic material was confirmed. A fiberglass post was installed $4 \mathrm{~mm}$ beyond the perforation level, and the tooth was permanently restored. The clinical and plus radiographic exams at the one-year follow-up indicated healing of the lesion, and no symptoms were present (Fig. 2p).

\section{Case 2}

A healthy 32-year-old male patient was referred to the endodontic clinic at PUC Minas for the diagnosis and treatment of buccal and distal perforations of the tooth \#12. His medical history was noncontributory. A clinical examination revealed no significant periodontal probing depth (Fig. 3a). However, a high level of intra-canal contamination was observed after removing a preexisting provisional crown under DOM (Fig. 3b).

Preoperative DR (Digital XDR ${ }^{\circledR}$ System, São Paulo, Brazil), performed at different angles, indicated the presence of PCC and a deviation at the middle cervical third of the root in the Bucco-mesial direction and the presence of a circumscribed radiolucent area (Fig. 3c, 3d). CBCT images were requested to examine the relationship of the perforation to adjacent structures and the extent of bone loss (Fig. 3e-3g).

The clinical findings and prognosis were discussed with the patient, and consent for the procedures was obtained. Perforation management was performed as described in Case 1. The canal was identified under DOM, and the root canal working length was decided using the electronic apex locator Root ZX2 (J Morita) and periapical radiography (Fig. 3h, 3i). The mechanical chemical preparation and obturation were identical to those in Case 1 (Fig. 3j$30)$. In contrast to Case 1, however, the perforation was sealed before root canal obturation due to its position and proximity to the canal. At the one-year follow-up, the patient was completely asymptomatic and DR images suggested a reduction in the radiolucent area close to the perforation (Fig. 3p).

\section{Discussion}

Root perforation is defined by the American Association of Endodontists as the mechanical or pathological communication between the root canal system and the external tooth surface (17). The causes of perforation include caries, root resorption, or iatrogenic accidents used during root canal treatment (18). Accidental root perforations occur in approximately $2 \%-12 \%$ of endodontically treated teeth (19). In teeth with PCC, this usually occurs when the dental professional has difficulties in locating the canal and tangentially deviates from it, inadvertently creating a "false" canal (Case 1 and 2) (16).

Root perforation prognosis depends on the size and location of the defect, the time of exposure to contamination, and the material used for repair $(18,19)$. In addition, it is important to evaluate accessibility to the canal and the possibility of sealing the defect. However, success can be severely influenced by adverse events that may occur during root management (14).

Depending on the proximity of the gingival sulcus to the perforation, contamination, and apical migration of the epithelium to the perforation site can occur, resulting in a periodontal defect (20). This is consistent with the Fuss and Trope classification, in which worse prognoses for bone crest region perforations have been described (21). In the reported cases, the perforations were located at the medio-cervical third of the root, but a periodontal pocket was not present, which favors the healing process after treatment completion. Unfortunately, the time the perforation occurred could not be precisely determined in the reported cases. One could hypothesize that the root canal was perforated during primary endodontic therapy, but the degree and extent of the contamination time could not be determined.

Bioceramics do not perform well at inflamed sites (22). Controlling excessive bleeding, therefore, is fundamental 


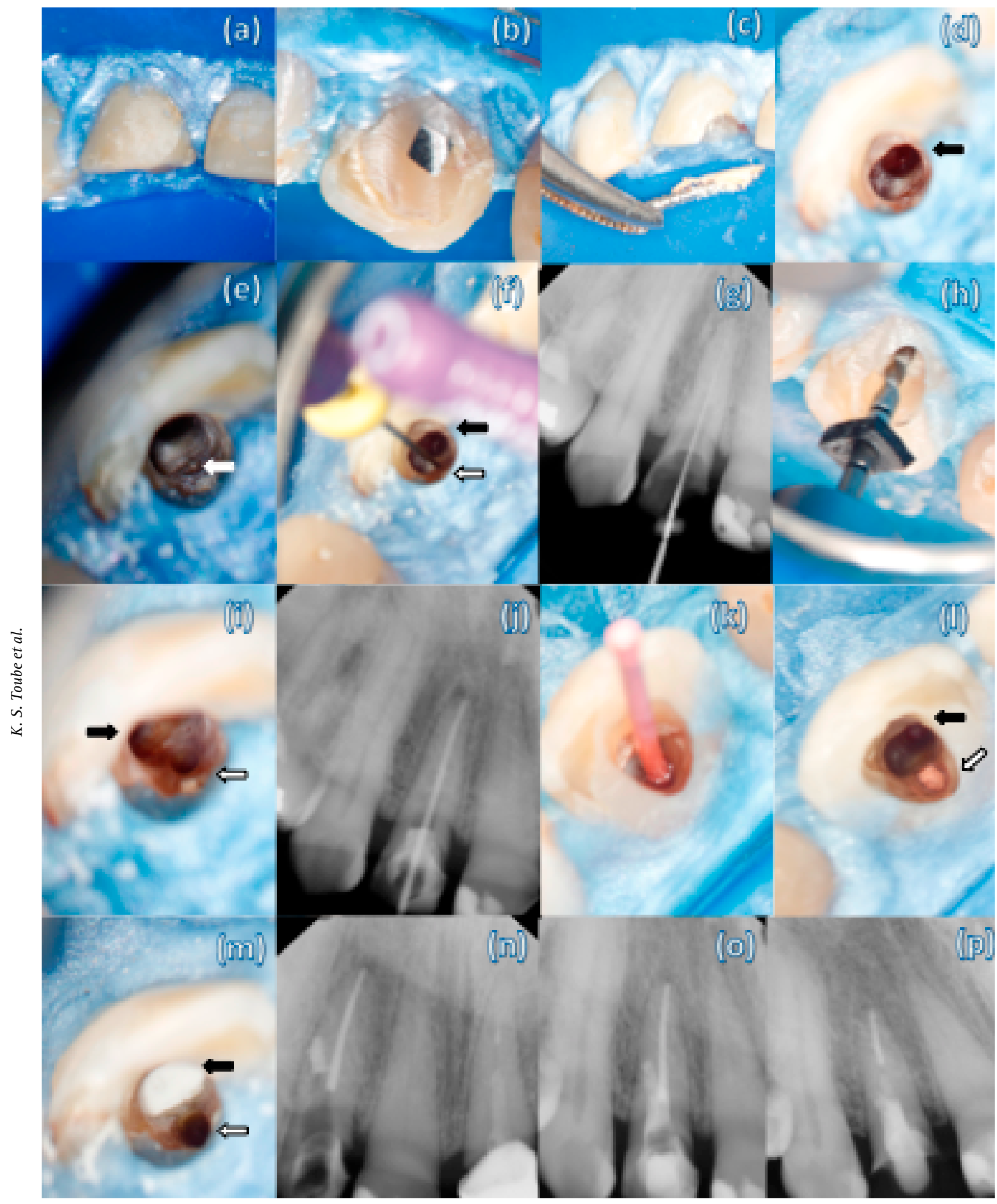

Figure 3: the preoperative image of the maxillary right lateral incisor area indicating the absence of a periodontal pocket (a). A high level of intracanal contamination was clinically detected (b). Digital periapical radiographs were performed at multiple angles (c,d). Axial (e,f), and sagittal (g) CBCT images revealing lateral perforation in the cervical root third associated with the radiolucent area (arrows). The perforation (black arrow) and the canal (white arrow) were identified (h). Working length was confirmed by digital radiographic imaging (i). The main canal was cleaning and shaping (white arrow) (j). Both canal and the perforation were dressed with $\mathrm{Ca}(\mathrm{OH}) 2(\mathrm{k})$. A paper point was kept inside the perforation to prevent the Bio-C sealer from falling in during the repair procedure (l). The perforation was sealed with Bio-C Repair (blackarrow) and the main canal (white arrow) was sealed with gutta-percha point (m). The lateral deviation was rebuilt with composite resin (n). A postoperative periapical radiograph was taken after the canal and perforation fillings (o). One-year follow-up radiographic image indicating a reduction of the radiolucent area close to the perforation (p). 
for the correct filling and identification of the perforation limits (21). In both cases, the limits of the perforation cavity were dried using paper tips and hemostatic agents. Only after bleeding was controlled were the cavities filled with bioceramics. The application of a calcium hydroxide dressing before drilling, which was performed in both cases, allowed for the neutralization of the environment, favoring the properties of bioceramics (24).

The optional use of barriers to prevent further extrusion of material into the surrounding tissues (23) was not done for these cases. Unfortunately, in case 2, extrusion of the bioceramics occurred, although it did not appear to affect healing, as indicated by the clinical examination and radiography follow-up. The treatment plan for these two related cases was carried out in different stages. In the first case, the drilling selector was performed after obtaining the root canal, while in the second case, drilling was selected before obtaining the root canal. The choice of this sequence depends on the view, position, and proximity of the drilling to the canal.

Due to the limitations of MTA $(3,4)$, bioceramic endodontic materials have emerged as alternative cement that can be used for repair $(4,11,14)$. Bio-C Repair is a cement with the considerable advantage of being supplied in a ready-to-use form (putty). The chemical composition, ultrastructural morphology, biocompatibility, and human dental pulp effects of Bio-C Repair were compared to Biodentine and ProRoot MTA. Bio-C Repair was found to mainly be composed of carbon (34.81\%) and oxygen $(34.51 \%)$, with a lower concentration of calcium compared to the other biomaterials, which mainly contain oxygen and calcium. Bio-C Sealer, which is an endodontic sealer, also had a higher concentration of calcium; therefore, this characteristic composition of Bio-C Repair may be associated with a higher capacity for tissue repair (9). This finding corroborates previous studies in which Bio-C Repair showed greater viability, adhesion, and cell migration rates compared to Bio-CSealer (12). It was also observed that fast setting pastes, such as EndoSequence Root Repair Material Putty and Biodentine did not induce perceptible tooth discoloration when left in the pulp chamber for periods of up to six months (10).

In conclusion, the new bioceramic Bio-C Repair was able to facilitate and accelerate the management of endodontic complications in its ready-to-use form $(6,15)$, simplifying the procedure and saving time. Future long-term observational studies are recommended to increase the available evidence demonstrating the successful use of this repair cement. Within the limits of this study, it aimed to contribute to the clinical knowledge of alternative approaches to lateral root perforation repair by discussing two cases of anterior teeth with PCC. These cases demonstrated that Bio-C Repair could be an effective therapeutic alternative to MTA, as observed at one-year follow-ups.

\section{Resumo}

0 presente relato de caso teve como objetivo descrever o manejo da perfuração lateral no terço médio cervical da raiz em dois incisivos superiores com calcificação pulpar utilizando o Bio-C Repair, com estratégias de tratamento clínico seguras e viáveis. Radiografias digitais foram obtidas em diferentes ângulos e analisadas com diferentes filtros. Imagens de tomografia computadorizada de feixe cônico (TCFC) foram solicitadas para mostrar a real posição do canal e a localização da perfuração, e orientar o planejamento estratégico do caso. Posteriormente, o acesso à cavidade foi preparado com auxílio de microscopia cirúrgica. Após a identificação da perfuração, o tecido de granulação foi removido, o canal original foi identificado e, em seguida, recebeu medicação intracanal à base de hidróxido de cálcio. Na segunda visita, a perfuração foi selada com Bio-C Repair e o sistema de canais obturado com cones de guta-percha e cimento endodôntico (Bio-C Sealer). Os dentes foram restaurados com pino de fibra de vidro, $4 \mathrm{~mm}$ além do nível da perfuração, e coroas provisórias. Ambos os dentes tratados conforme descrito acima se mostraram funcionais e assintomáticos na avaliação clínica e radiográfica de 1 ano. 0 Bio-C Repair é sugerido como uma nova opção de cimento endodôntico para o manejo de perfurações laterais, com resultados efetivos observados após um ano de acompanhamento.

\section{References}

1. Chen $\mathrm{S}$, Shi L, Luo J, Engqvist $\mathrm{H}$. Novel fast-setting mineral trioxide aggregate: its formulation, chemical-physical properties, and cytocompatibility. ACS Appl Mater Interfaces 2018;10:20334-20341.

2. Torabinejad $M$, Parirokh $M$, Dummer PMH. Mineral trioxide aggregate and other bioactive endodontic cements: an updated overview - part II: other clinical applications and complications. Int Endod J 2018;51:284-317.

3. Kogan P, He J, Glickman GN, Watanabe I. The effects of various additives on setting properties of MTA. J Endod 2006;32:569-572.

4. Jitaru $S$, Hodisan I, Timis L, Lucian A, Bud M. The use of bioceramics in endodontics - literature review. Clujul Med 2016;89:470-473.

5. Lovato KF, Sedgley CM. Antibacterial activity of endosequence root repair material and proroot MTA against clinical isolates of Enterococcus faecalis. J Endod 2011;37:1542-1546.

6. Leal F, De-Deus G, Brandão C, Luna A, Souza E, Fidel S. Similar sealability between bioceramic putty ready-to-use repair cement and white MTA. Braz Dent J 2013;24:362-366.

7. Guo YJ, Du TF, Li HB, Shen Y, Mobuchon C, Hieawy A, et al. Physical properties and hydration behavior of a fast-setting bioceramic endodontic material. BMC Oral Health 2016;16:23-28.

8. McMichael GE, Primus CM, Opperman LA. Dentinal tubule penetration of tricalcium silicate sealers. J Endod 2016;42:632-636.

9. Ghilotti J, Sanz JL, López-Garcia S, Guerrero-Gironés J, Pecci-Lloret MP, Lozano A, et al. Comparative Surface Morphology, Chemical composition, and cytocompatibility of bio-c repair, biodentine, and proroot MTA on hDPCs. Materials 2020;13:2189.

10. Kohli MR, Yamaguchi M, Setzer FC, Karabucak B. Spectrophotometric analysis of coronal tooth discoloration induced by various bioceramic cements and other endodontic materials. J Endod 2015;41:1862-1866.

11. Walsh RM, He J, Schweitzer J, Opperman LA, Woodmansey KF. Bioactive endodontic materials for everyday use: a review. Gen Dent 2018;66:4851.

12. Lopez-Garcia S, Lozano A, Garcia-Bernal D, Forner L, Llena C, GuerreroGirones J, et al. Biological effects of new hydraulic materials on human periodontal ligament stem cells. J Clin Med 2019;8:1-13.

13. Mendes AT, Silva PBD, Só BB, Hashizume LN, Vivan RR, Rosa RAD, et al. Evaluation of physicochemical properties of new calcium silicate-based sealer. Braz Dent J 2018;29:536-540.

14. Kakani AK, Veeramachaneni C, Majeti C, Tummala M, Khiyani L. A review on perforation repair materials. J Clin Diagn Res 2015;9:Ze09-13. 
15. Benetti F, Queiroz IOA, Cosme-Silva L, Conti LC, Oliveira SHP, Cintra LTA. Cytotoxicity, biocompatibility and biomineralization of a new ready-foruse bioceramic repair material. Braz Dent J 2019;30:325-332.

16. de Toubes KMS, de Oliveira PAD, Machado SN, Pelosi V, Nunes E, Silveira FF. Clinical approach to pulp canal obliteration: A case series. Iran Endod J 2017:12:527-533.

17. Endodontists AAo. Glossary of endodontic terms: American Association of Endodontists; 2003.

18. Bryan EB, Woollard G, Mitchell WC. Nonsurgical repair of furcal perforations: a literature review. Gen Dent 1999;47:274-278.

19. Farzaneh $\mathrm{M}$, Abitbol $\mathrm{S}$, Friedman $\mathrm{S}$. Treatment outcome in endodontics: the Toronto study. Phases I and II: Orthograde retreatment. J Endod 2004;30:627-633.

20. Menezes $R$, da Silva Neto UX, Carneiro E, Letra A, Bramante CM, Bernadinelli N. MTA repair of a supracrestal perforation: a case report. J
Endod 2005;31:212-214.

21. Fuss Z, Trope M. Root perforations: classification and treatment choices based on prognostic factors. Endod Dent Traumatol 1996;12:255-264.

22. Chng HK, Islam I, Yap AUJ, Tong YW, Koh ET. Properties of a new root-end filling material. J Endod 2005;31:665-668.

23. Sjogren U, Figdor D, Spangberg L, Sundqvist G. The antimicrobial effect of calcium hydroxide as a short-term intracanal dressing. Int Endod J 1991;24:119-125

24. Wang Z, Shen $Y$, Haapasalo M. Dentin extends the antibacterial effect of endodontic sealers against Enterococcus faecalis biofilms. J Endod 2014;40:505-508.

Received August 12, 2020 Accepted November 30, 2020 